\title{
SELEÇÃO DE LINHAGENS EXPERIMENTAIS DE SOJA PARA CARACTERÍSTICAS AGRONÔMICAS E TOLERÂNCIA A INSETOS ( $\left.{ }^{1}\right)$
}

\author{
MARIA CLIDEANA CABRAL MAIA $\left({ }^{2 *}\right)$; NATAL ANTONIO VELLO $\left({ }^{3}\right)$; \\ MAURISRAEL DE MOURA ROCHA $\left({ }^{4}\right)$; NELSON SILVA DA FONSECA JÚNIOR $\left({ }^{5}\right)$; \\ OSMIR JOSÉ LAVORANTE ( $\left(^{6}\right)$; JOSÉ BALDIN PINHEIRO (3); CARLOS TADEU DOS SANTOS DIAS (7); \\ GISELLE MARIANO LESSA DE ASSIS ( $\left.{ }^{2}\right)$
}

\begin{abstract}
RESUMO
Esta pesquisa visou avaliar linhagens experimentais de soja, com a finalidade de identificar genótipos que reúnam características de alta produtividade e tolerância a insetos. O material foi composto por três populações obtidas de um dialelo parcial $4 \times 4$ envolvendo quatro genitores tolerantes a insetos e quatro cultivares de elevada produtividade. Foram conduzidos 24 experimentos no delineamento aleatório, em blocos com duas repetições subdivididas em conjuntos experimentais com testemunhas comuns, combinando as três populações e oito ambientes. Com base na produtividade de grãos, concluiuse que: existe variabilidade genética remanescente entre as linhagens nas três populações; o manejo diferenciado com controle intensivo de insetos e controle ecológico de insetos (CII vs. CEI) é um representante eficiente de ambientes diversos; o local Anhembi destacou-se como de alta produtividade em todas as situações; para a capacidade de gerar linhagens superiores, sobressaíram-se os genitores IAC-100, D72-9601-1, BR-6, Davis e IAS-5; destaques especiais envolveram os cruzamentos do genitor IAC-100 com IAS-5, Davis, OCEPAR-4 e BR-6.
\end{abstract}

Palavras-chave: Glycine max, população segregante e análise univariada.

\section{ABSTRACT \\ SOYBEAN EXPERIMENTAL LINES SELECTED FOR AGRONOMIC TRAITS AND INSECT TOLERANCE}

This research aimed to evaluate experimental soybean lines, with the finality to identify genotypes that contine traits of elevate yield and insect tolerance. Plant material included three populations derived from a $4 \times 4$ partial diallel having four parents insect resistants and four with elevated yield cultivars. The 24 experiments were carried out in randomized complete block design with two replications subdivided in three sets with common checks, testing the three populations in eight environments. There is genetic variability among lines in the three populations; the management systems were efficient as representative of the environmental diversity; the Anhembi location exhibited with high seed yield in all situations; as for the ability in originating superior lines, the following parents stand out: IAC-100, D72-9601-1, BR-6, Davis, and IAS-5; the best outstanding biparental crosses occurred when the IAC-100 parent was crossed with IAS-5, Davis, OCEPAR-4, and BR-6.

Key words: Glycine max, segregant population and univariate analysis.

$\left({ }^{1}\right)$ Parte da tese de doutorado do primeiro autor, apresentada à Universidade de São Paulo, Escola Superior de Agricultura "Luiz de Queiroz" (ESALQ/USP). Recebido para publicação em 12 de junho de 2006 e aceito em 16 de outubro de 2008.

$\left({ }^{2}\right)$ Embrapa Acre - CPAFAC, Caixa Postal 321, 69900-970 Rio Branco (AC). E.mail: clideana@cpafac.embrapa.br (*) Autora Correspondente; giselle@cpafac.embrapa.br.

$\left({ }^{3}\right)$ Departamento de Genética, ESALQ/USP, Caixa Postal 9, 13418-900 Piracicaba (SP). E.mail: naavello@esalq.usp.br;baldin@esalq.usp.br

$\left({ }^{4}\right)$ Embrapa Meio Norte, Av. Duque de Caxias, 5650, Buenos Aires, 64006-220 Teresina (PI). E.mail: mmrocha@cpamn.embrapa.br.

$\left({ }^{5}\right)$ IAPAR - Instituto Agronômico do Paraná, Caixa Postal 418, 86047-900 Londrina (PR). E.mail: nsfjr@iapar.br.

$\left({ }^{6}\right)$ Embrapa Floresta, Caixa Postal 319, 83411-000 Colombo (PR). E.mail: osmir@cnpf.embrapa.br

$\left({ }^{7}\right)$ Departamento de Ciências Exatas - ESALQ/USP, Caixa Postal 9, 13418-900 Piracicaba (SP). E.mail: ctsdias@esalq.usp.br. 


\section{INTRODUÇÃO}

A soja [Glycine max (L.)] é uma das espécies de maior importância econômica no contexto mundial. Devido a essa condição especial, tal cultura conseguiu se aproximar mais da maximização da produtividade, através da associação do uso racional e eficiente do ambiente com o melhoramento genético. É importante ressaltar que o uso de novas cultivares não representa custos adicionais aos agricultores (Vello, 1992). Atualmente, o Brasil é o maior produtor mundial de grãos dessa leguminosa, com uma produção de 58 milhões de toneladas em 2007, sendo o rendimento médio equivalente a $2.816 \mathrm{~kg} \mathrm{ha}^{-1}$ (IBGE, 2008).

Nos programas de melhoramento maior ênfase tem sido dada aos caracteres relacionados à produtividade de grãos e ao fotoperíodo. Contudo, a ocorrência de pragas e doenças tem se tornado fator limitante da produção. Desse modo, existe uma tendência de se dar maior atenção à incorporação destas características de resistência, no sentido de torná-las também fatores estabilizadores da produtividade.

Informações a respeito dos mecanismos genéticos da resistência são de grande interesse em várias etapas dos programas de melhoramento e podem auxiliar na identificação de fontes de resistência; orientar cruzamentos e seleção de progênies; ampliar a base genética com inclusão de acessos resistentes, assim como, desenvolver linhagens isogênicas que podem ser usadas no estudo de mecanismos de resistência.

A resistência de plantas é regra na natureza e os mecanismos que conferem essa proteção sobrepõem sistematicamente os mecanismos ou "armas" de ataque das pragas, de maneira que uma cultivar possui diversos meios para resistir ao ataque de uma praga.

Dada a importância da identificação dos mecanismos de resistência a insetos em linhagens e ou cultivares para programas de melhoramento genético que buscam desenvolver cultivares de soja resistentes e/ou tolerantes, estudos desses eventos têm sido comuns, sendo a antixenose (ou não-preferência) verificada para as pragas Anticarsia gemmatalis (ARIEL, 1990); já a resistência do tipo antibiose foi identificada para Heliothis virescens (Beland e Hatchett, 1976), e para Epilachna varivestis (BURDEN e NoRRIS, 1994).

Apesar da importância dos inseticidas no controle de pragas como os percevejos sugadores (Piezodorus guildinii, Nezara viridula e Euschistus heros) e insetos mastigadores de folhas como as lagartas (Anticarsia gemmatalis) e besourinhos (Colaspis sp., Cerotoma arcuata, Diabrotica speciosa e Diphaulaca viridipennis), seu uso intensivo tem sido ecologicamente nocivo, causando o surgimento de resistência nos insetos aos produtos empregados, além de permanecer resíduos indesejáveis no ambiente. Uma estratégia adicional é representada pela resistência genética das plantas de soja aos insetospragas. As primeiras evidências experimentais indicam que a herança da tolerância da soja ao complexo de percevejos é de natureza poligênica e aditiva (Souza e Toledo, 1995). No Brasil, a primeira cultivar com resistência moderada a insetos sugadores e mastigadores foi a IAC 100. Outros genótipos com tolerância a insetos são genótipos com adaptação restrita às condições ambientais norte-americanas: Crokett, Lamar e D 72-9601-1.

É bem conhecido na literatura que materiais genéticos selecionados para resistência/tolerância comumente resultam em menor produtividade, na ausência de pragas. Geralmente, genes para resistência a insetos são mais frequentemente observados em materiais exóticos, comumente ligados a outros genes desfavoráveis do ponto de vista de caracteres adaptativos e agronômicos. Esse fato obriga o uso de várias gerações adicionais, geralmente através de retrocruzamentos, para quebrar as mencionadas ligações genéticas, o que desestimula o uso de materiais exóticos nos programas de melhoramento.

Os seguintes fatos podem ser considerados como justificativas para pesquisas envolvendo o desenvolvimento e estudo de novos genótipos de soja com tolerância a insetos: a) número restrito (um) de cultivares de soja tolerantes a insetos, insuficiente para atender a uma área cultivada que se estende de $33^{\circ} \mathrm{Sul}$ a $4^{\circ}$ Norte de Latitude; b) evidências de um controle genético da tolerância a insetos; c) importância da tolerância a insetos sobre a produtividade de grãos e outros caracteres em soja.

Esta pesquisa visa avaliar linhagens experimentais de soja, com a finalidade de identificar genótipos que reúnam características de alta produtividade e tolerância a insetos mastigadores e sugadores.

\section{MATERIAL E MÉTODOS}

O material genético envolve três tipos de populações obtidas a partir de um dialelo parcial $4 \times 4$ desenvolvido com a finalidade de reunir os genes de tolerância/resistência a insetos presentes em quatro genitores (IAC-100, Crockett, Lamar e D72-9601-1), com genes para desempenho agronômico favorável (principalmente, produtividade de grãos e precocidade) presentes em quatro cultivares com elevada produtividade - BR-6, IAS-5, Davis, Ocepar- 
4 (Tabela 1). Genótipos dos 16 cruzamentos do dialelo parcial foram avaliados em vários locais. Foram utilizadas três testemunhas comuns: Primavera, IAS5 e IAC- 100 .

Este estudo faz parte das linhas de pesquisa do Setor de Genética Aplicada às Espécies Autógamas do Departamento de Genética da ESALQ/USP. A diferenciação principal entre as três populações aconteceu na geração $F_{2}$, na qual foram empregados três procedimentos distintos de seleção de plantas individuais, conforme relatado a seguir:

- PCI (populações com controle de insetos): originadas da seleção para produtividade de grãos, a partir de 72 plantas $F_{2}$ de cada um dos 16 cruzamentos, com cultivo em covas na ESALQ; neste caso, aplicou-se inseticidas durante o ciclo total para o controle de insetos mastigadores e sugadores;

Tabela 1. Identificação das linhagens (P1 a P20) das populações PCI (formada a partir de plantas $\mathrm{F}_{2}$ obtidas com controle total de insetos), PRIS (formada a partir de plantas $F_{2}$ selecionadas para tolerância a insetos sugadores) e PRIM (formada a partir de plantas $\mathrm{F}_{2}$ selecionadas para tolerância a insetos mastigadores) e testemunhas

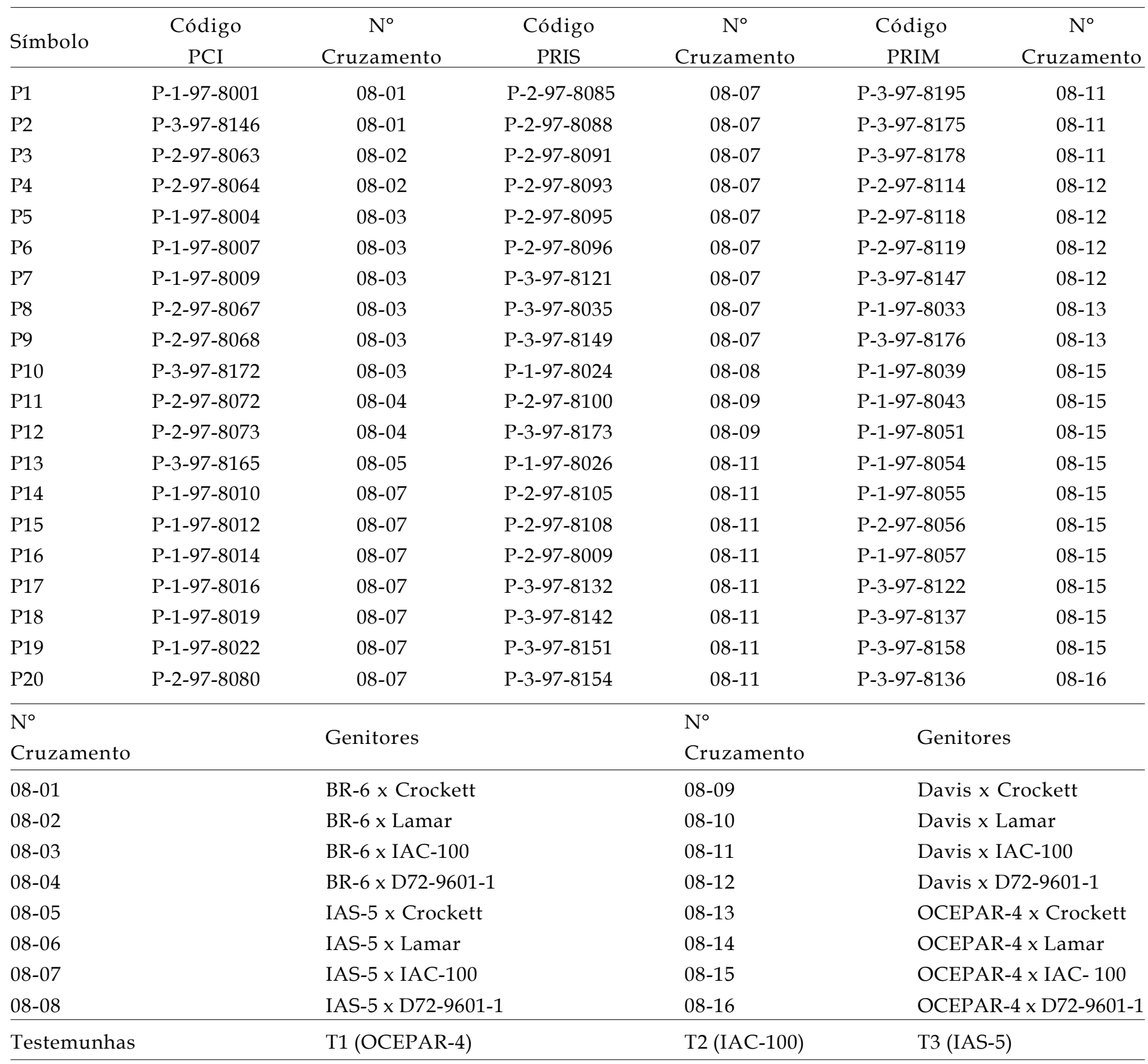


- PRIS (populações selecionadas para resistência a insetos sugadores): obtidas pela seleção feita para tolerância a insetos sugadores entre 72 plantas $\mathrm{F}_{2}$ de cada um dos 16 cruzamentos, com cultivo em covas em Mococa - SP (Estação Experimental do IAC); estas plantas receberam aplicações de inseticidas apenas durante o ciclo vegetativo, com a finalidade de controlar insetos mastigadores;

- PRIM (populações selecionadas para resistência a insetos mastigadores): sintetizadas após a seleção para tolerância a insetos mastigadores (principalmente, lagartas) realizada entre 72 plantas $\mathrm{F}_{2}$ de cada um dos 16 cruzamentos, com cultivo em covas em Campinas - SP (Centro Experimental do IAC); iniciou-se a aplicação de inseticidas após o florescimento, com a finalidade de controlar insetos sugadores.

A partir da geração $F_{3}$, promoveu-se seleção principalmente para produtividade de grãos e tolerância ao fotoperíodo. Os experimentos conduzidos em 1999/00 incluíram 120 linhagens experimentais, na geração $\mathrm{F}_{10}$, sendo 40 linhagens de cada tipo de população (PCI, PRIS e PRIM); os experimentos, conduzidos em 2000/01 envolveram um total de 60 linhagens $F_{11}$, sendo 20 linhagens selecionadas em cada uma das três populações, com base nos resultados obtidos no ano agrícola anterior.

Os 24 experimentos do presente estudo foram desenvolvidos em dois locais do município de Piracicaba, SP (Estação Experimental Anhembi e Fazenda Areão), durante dois anos agrícolas $(1999 / 00,2000 / 01)$ e em dois sistemas de manejo (com controle intensivo de insetos e com controle ecológico de insetos).

Nos experimentos com controle intensivo de insetos (CII), com base em monitoramento freqüente, promoveu-se a aplicação de inseticidas sempre que se detectaram insetos mastigadores e ou dois percevejos $/ \mathrm{m}^{2}$ de pano (método do pano de batida).

Nos experimentos com controle ecológico de insetos (CEI), promoveu-se a aplicação de inseticidas apenas quando se observou a ocorrência de grande quantidade de danos nas folhas causadas por insetos mastigadores e ou quando a infestação natural atingiu quatro percevejos $/ \mathrm{m}^{2}$ de pano.

Todos os experimentos foram desenvolvidos no delineamento aleatorizados em blocos, com as repetições estratificadas em conjuntos experimentais com testemunhas comuns.
O modelo matemático adotado para a análise conjunta geral é apresentado conforme a Equação 1 a seguir:

$$
\begin{aligned}
& Y_{i k l n}=\mathrm{m}+t_{i}+a_{n}+l_{l}+(t l)_{i l}+(l a)_{l n}+c_{k(l n)}+ \\
& (c t)_{k i}+(t l a)_{t l n}+\mathrm{e}_{i k l n} \\
& \quad \text { sendo: }
\end{aligned}
$$

$Y_{i k l n}$ : observação referente à testemunha " $\mathrm{i}$ ", no conjunto experimental " $k$ ", no local " 1 ", no ano " $n$ "; $\mathrm{m}$ : média geral do caráter;

$t_{i}$ : efeito fixo da testemunha " $i$ ";

$a_{n}$ : efeito aleatório do ano " $\mathrm{n}$ "

$l_{l}$ : efeito fixo do local " 1 ";

$(t l)_{i l}$ : efeito fixo da interação entre a testemunha " $\mathrm{i}$ " e o local " 1 ";

$(l a)_{l n}$ : efeito aleatório da interação entre o local "1" e o ano "n";

$c_{k(l n)}$ : efeito aleatório do conjunto " $\mathrm{k}$ ", dentro do ano " $\mathrm{n}$ ", dentro do local " 1 ";

$(c t)_{k i}$ : efeito aleatório da interação entre o conjunto " $k$ " e a testemunha " $\mathrm{i}$ ";

$(t l a)_{i l n}$ : efeito aleatório da interação tripla entre a testemunha "i", o local " 1 " e o ano " $\mathrm{n}$ ";

$\mathrm{e}_{i k l n}$ : Efeito aleatório do erro experimental médio associado à parcela "ikln", admitido ser independente e com distribuição normal de média zero e variância.

Os dados de produtividade de grãos, em $\mathrm{kg}$ $\mathrm{ha}^{-1}$, foram submetidos a análises de variância individuais, dentro de cada tipo de população, manejo, local e ano agrícola.

O modelo adotado para a análise individual de variância foi o seguinte:

$$
Y_{i j k}=\mathrm{m}+G_{i}+r_{j}+c_{k}(j)+\mathrm{e}_{i j k}
$$

sendo:

$\mathrm{Y}_{\mathrm{ijk}}$ : observação do genótipo "i" na repetição "j", no conjunto k;

m: média geral do caráter;

$\mathrm{G}_{\mathrm{i}}$ : efeito fixo da linhagem " $\mathrm{i}$ "; $i=1, \ldots, \mathrm{g}$;

$\mathrm{r}_{\mathrm{j}}$ : efeito aleatório da repetição " $\mathrm{j}$ "; $\mathrm{j}=1, \ldots, \mathrm{J}$;

$c_{k}\left({ }_{j}\right)$ : efeito aleatório de conjunto " $k$ " dentro de repetição "j"; $k=1, \ldots, \mathrm{K}$;

$\mathrm{e}_{\mathrm{ijk}}$ erro experimental associado à parcela "ijk", admitido ser independente e com distribuição normal de média zero e variância. 
Em seguida, foi realizada a análise conjunta de variância para populações (POP), sistemas de manejos (M), locais (L) e anos (A), tendo como principal objetivo estimar as possíveis interações entre linhagens, locais, anos e manejos. O modelo matemático foi utilizado de acordo com a equação 3 a seguir:

$$
Y_{\text {pikjmln }}=\mathrm{m}+P_{p}+G_{i}(P)_{p}+M_{m}+(P M)_{p m}+
$$
$M G_{m i}(P)_{\mathrm{p}}+A_{n}+(P A)_{p n}+A G_{n i}(P)_{p}+(M A)_{m n}+(P M A)_{p m n}$ $+M A G_{m n i}(P)_{\mathrm{p}}+L_{l}+(P L)_{p l}+L G_{l i}(P)_{p}+(M L)_{m l}+$ $(P M L)_{p m l}+M L G_{m l i}(P)_{p}+(A L)_{n l}+(P A L)_{p n l}+A L G_{n l i}(P)_{p}+$ $(M A L)_{m n l}+(P M A L)_{p m n l}+M A L G_{m n l i}(P)_{p}+R_{j} / M_{m} / A_{n} / L_{l}+$ $C_{k} / M_{m} / A_{n} / L_{l} / R_{j}+\mathrm{e}_{\text {pikjmln }}$

em que:

$Y_{\text {pikjmln }}$ : observação da população " $\mathrm{p}$ ", do genótipo " $\mathrm{i}$ ", no conjunto " $\mathrm{k}$ ", na repetição " $\mathrm{j}$ ", no manejo " $m$ ", no local " 1 ", no ano " $n$ ";

m: média geral do caráter;

$G_{i}$ : efeito fixo de genótipo " $\mathrm{i}$ ";

$G_{i}(P)_{p}$ : efeito fixo de genótipo " $\mathrm{i}$ " dentro de população " $\mathrm{p}$ ";

$M_{m}$ : efeito fixo de manejo " $\mathrm{m}$ ";

$(P M)_{p m}$ : efeito fixo da interação entre população " $\mathrm{p}$ " e o manejo " $\mathrm{m}$ ";

$M G_{m i}(P)_{\mathrm{p}}$ : efeito fixo da interação entre manejo " $m$ " e o genótipo " $i$ " dentro de população " $p$ ";

$A_{n}$ : efeito aleatório do ano " $\mathrm{n}$ ";

$(P A)_{p n}$ : efeito aleatório da interação entre população "p" e ano "n";

$A G_{n i}(P)_{p}$ : efeito aleatório da interação entre ano " $n$ " e genótipo " $i$ " dentro de população " $p$ ";

$(M A)_{m n}$ : efeito aleatório da interação entre manejo "m" e ano " $\mathrm{n}$ ";

$(P M A)_{p m n}$ : efeito aleatório da interação entre população " $p$ ", manejo " $\mathrm{m}$ " e ano " $\mathrm{n}$ ";

$M A G_{m n i}(P)$ : efeito aleatório da interação entre manejo " $m$ ", ano " $n$ " e genótipo " $i$ " dentro de população "p";

$L_{l}$ : efeito fixo do local " 1 ";

$(P L)_{p l}$ : efeito fixo da interação entre população "p" e local "1";

$L G_{l i}(P)_{p}$ : efeito fixo da interação entre local " 1 " e genótipo "i" dentro de população " $\mathrm{p}$ ";

$(M L)_{m l}:$ efeito fixo da interação entre manejo "m" e local "l";
$(P M L)_{p m l}$ : efeito fixo da interação entre população " $p$ ", manejo " $m$ " e local " 1 ";

$M L G_{m l i}(P)_{p}$ : efeito fixo da interação entre manejo " $\mathrm{m}$ ", local " 1 " e genótipo " $\mathrm{i}$ " dentro de população " $\mathrm{p}$ ";

$(A L)_{n l}$ : efeito aleatório da interação entre anos "n" e local " 1 ";

$(P A L)_{p n l}$ : efeito aleatório da interação entre população " $\mathrm{p}$ ', ano " $\mathrm{n}$ " e local " 1 ";

$A L G_{n l i}(P)_{p}$ : efeito aleatório da interação entre ano " $n$ ", local "l" e genótipo "i" dentro de população "p";

$(M A L)_{m n l}$ : efeito aleatório da interação entre manejo " $\mathrm{m}$ ", ano " $\mathrm{n}$ " e local " 1 ";

$(P M A L)_{p m n l}$ : efeito aleatório da interação entre população " $\mathrm{p}$ ", manejo " $\mathrm{m}$ ", ano " $\mathrm{n}$ " e local " 1 ";

$M A L G_{m n l i}(P)_{p}$ : efeito aleatório da interação entre manejo " $m$ ", ano " $n$ ", local " 1 " e genótipo " $\mathrm{i}$ " dentro de população " $p$ ",

$R_{j} / M_{m} / A_{n} / L_{l}$ : efeito de repetição "j" dentro de manejo " $\mathrm{m}$ " dentro de ano " $\mathrm{n}$ ' dentro de local " $\mathrm{l}$ ';

$C_{k} / M_{m} / A_{n} / L_{l} / R_{j}$ : efeito de conjunto " $k$ " dentro de manejo " $\mathrm{m}$ " dentro de ano " $\mathrm{n}$ ' dentro de local " $\mathrm{l}$ ' dentro de repetição " $j$ ";

e pikjmln: erro aleatório experimental médio associado à parcela "pikjmln", admitido ser independente e com distribuição normal de média zero e variância.

Todas as análises de variância foram realizadas utilizando-se o procedimento GLM do programa SAS (Statistical Analysis System) (SAS INSTITUTE, 1997).

\section{RESULTADOS E DISCUSSÃO}

É sabido que, em populações continuamente submetidas à seleção, há um balanço dinâmico entre os componentes das variâncias genéticas. E a seleção será mais eficiente quanto maiores forem as variâncias aditiva e epistática aditiva $\times$ aditiva responsáveis pela fixação do caráter de interesse. Seguramente, pode-se inferir que em se tratando de caráter quantitativo, evidentemente muito influenciado pela ação do ambiente como o é a produtividade e tolerância a insetos, por exemplo, sua seleção deve ser postergada para gerações com níveis mais altos de endogamia. Se o interesse é explorar também a variação genética dentro das progênies, a seleção pode ser feita nas gerações iniciais dos ciclos reprodutivos naturais; tal procedimento é comumente empregado para caracteres qualitativos. 


\section{Análises Individuais}

As análises de testemunhas comuns foram eficientes em detectar diferenças entre conjuntos dentro das repetições, tendo sido encontrados efeitos significativos para testemunhas e para interação testemunhas $\times$ conjuntos. Portanto, tornou-se necessário o ajustamento das médias das linhagens em função das médias das testemunhas comuns dentro de cada conjunto experimental nos dois anos de estudo.

Os quadros das análises individuais e conjuntas estão apresentados nas tabelas 2 a 6 . Os coeficientes de variação experimental $(\mathrm{CV})$ referentes aos experimentos (Exp1, Exp2,...,Exp24), exceto para o Exp21 $(26,15)$ (Anhembi/2001-CII), atestam boa precisão no controle das causas de variação de ordem sistemática dos ambientes experimentais, uma vez que a maioria deles $(83.33 \%$ ) esteve abaixo de $20 \%$. Resultado que fornece segurança de coerência com o esperado para dados de produtividade de grãos, pois se trata de caráter quantitativo.

Nas análises individuais (Tabelas 2 a 4), além dos resíduos, as fontes de variação mais relevantes compreendem os efeitos "linhagens/cruzamentos", "testemunhas comuns" e o contraste "testemunhas vs. linhagens", sobre as quais estão concentradas as discussões a seguir.

Entre as testemunhas comuns (Tabela 2) foi detectada variação $(p<0,01)$ nos ambientes $\mathrm{E} 4$ e E6, e nos ambientes E1, E2 e E3 para $(\mathrm{p}<0,05)$; sendo as testemunhas bem contrastantes, é inerente maior grau de diferenças genéticas tanto para produtividade quanto para caracteres adaptativos. Apenas em E8 e nos ambientes E5 e E7 (ambos com controle intensivo de insetos) as testemunhas não diferiram significativamente entre si.

Para as linhagens dentro de cruzamentos foram detectadas diferenças significativas $(p<0,05)$ nos ambientes E3 e E4. A média das linhagens foi superior à média das testemunhas comuns nos ambientes E1, E3, E4, E5 e E6, sendo semelhantes em magnitude nos ambientes E7 e E8. Médias de produtividade altas e relativamente semelhantes entre as linhagens podem ser conseqüência do progresso genético acumulado com a prática de seleção durante as sucessivas gerações de endogamia na população PCI (controle total de insetos em $\mathrm{F}_{2}$ ).

Na tabela 3, verificam-se os resultados da análise individual para a população PRIS. Em relação à população anterior (PCI, Tabela 2), observa-se número maior de ambientes, todos envolvendo o local Areão (nos dois anos agrícolas e nos dois sistemas de manejo), com diferenças significativas entre linhagens dentro de cruzamentos (E3, E4, E7 e E8). As testemunhas também foram mais contrastantes entre si, pois detectaram-se diferenças significativas entre elas em sete ambientes contra cinco ambientes na tabela 2.

De acordo com a Tabela 4, em relação à população formada a partir de plantas $\mathrm{F}_{2}$ selecionadas para tolerância a insetos mastigadores (PRIM), as linhagens/cruzamentos foram significativamente variáveis $(p<0,01)$ apenas nos ambientes E1 e E3. Estes resultados são mais parecidos com aqueles da população PCI (Tabela 2) do que com os resultados de PRIS (Tabela 3). Nos ambientes E5 e E6, ambos no local Anhembi em 2000/2001, não houve níveis de variação para nenhuma fonte analisada; no caso particular de E5, o valor de CV $(26,15 \%)$ mais elevado dentre os 24 experimentos, pode ter sido responsável pela não-detecção de efeitos significativos para todas as fontes de variação.

Quanto às testemunhas comuns, foram observadas diferenças significativas ao nível de 1\% de probabilidade para os ambientes E1, E2, E3 e E7, e ao nível de 5\% para o ambiente E4 (Tabela 4). Os resultados verificados para as testemunhas nos experimentos da população PRIM (Tabela 4) também foram mais próximos àqueles obtidos na população PCI (Tabela 2) do que os da população PRIS (Tabela 3). Este fato pode ser interpretado como uma evidência de que existem diferenças ambientais entre as três séries de oito experimentos.

Na população PRIM, a pressão de seleção mais forte em $F_{2}$ foi feita para a característica resistência/tolerância a insetos mastigadores, avaliada com base em atribuição de notas (1: ataque estimado em 0 a $33 \% ; 2: 34 \%$ a $66 \%$ e $3: 64 \%$ a $100 \%$. Este critério é subjetivo e questionável visto que o caráter é quantitativo e, portanto, idealmente maior número de classes (notas) seria requerido para melhor representar sua variação contínua; além disso, a subjetividade poderia ser minimizada pelo uso de médias de várias avaliações independentes feitas por pesquisadores distintos.

Quanto às médias das linhagens da população PRIM, em relação às testemunhas comuns, foi constatado comportamento semelhante ao observado na população PRIS (Tabela 3), e em apenas três ambientes as linhagens superaram a média das testemunhas (Tabela 4 ).

Também, é possível comparar os 24 experimentos (Tabelas 2, 3 e 4) para o efeito "testemunhas vs. linhagens", juntamente com os contrastes entre médias de testemunhas e de linhagens. 


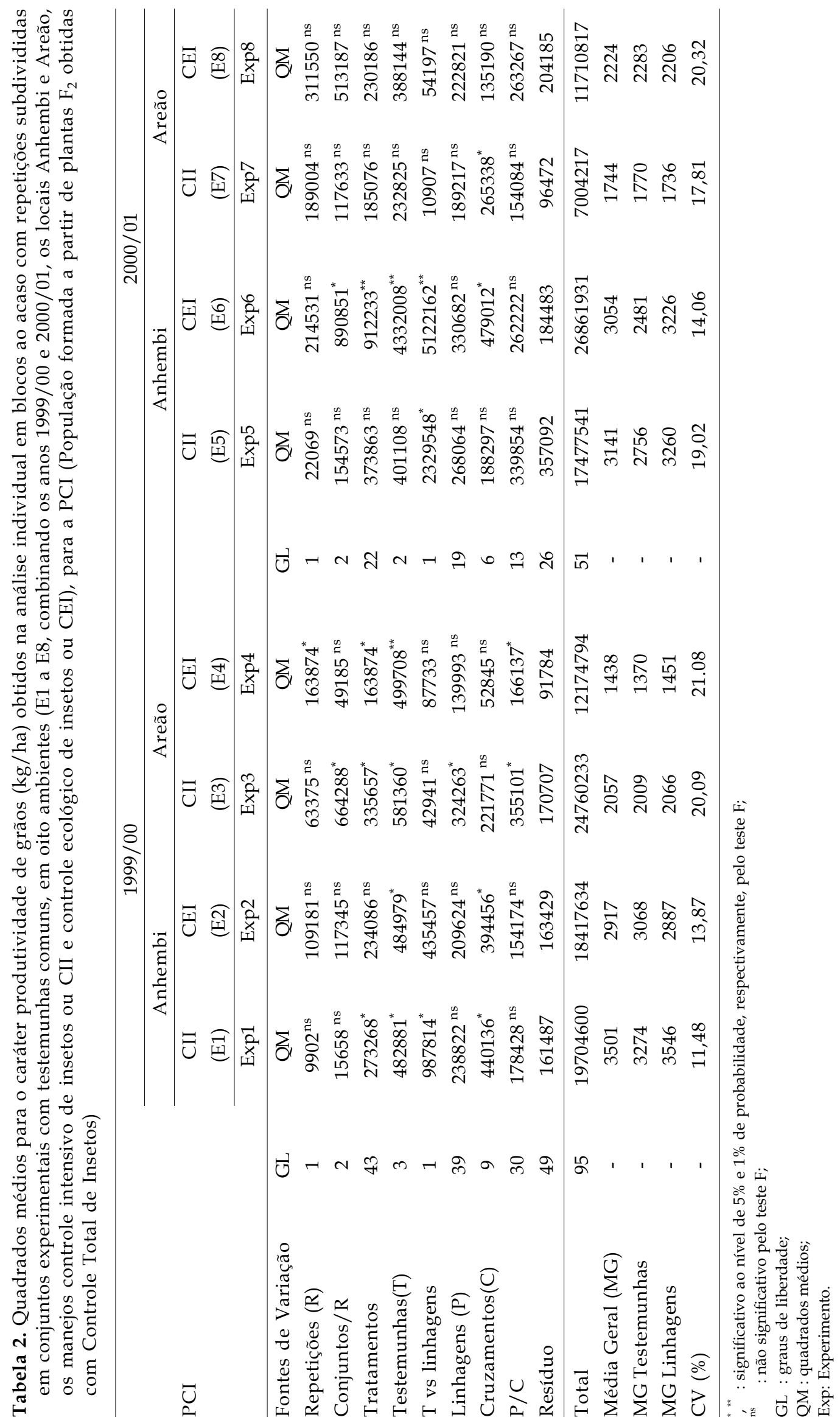




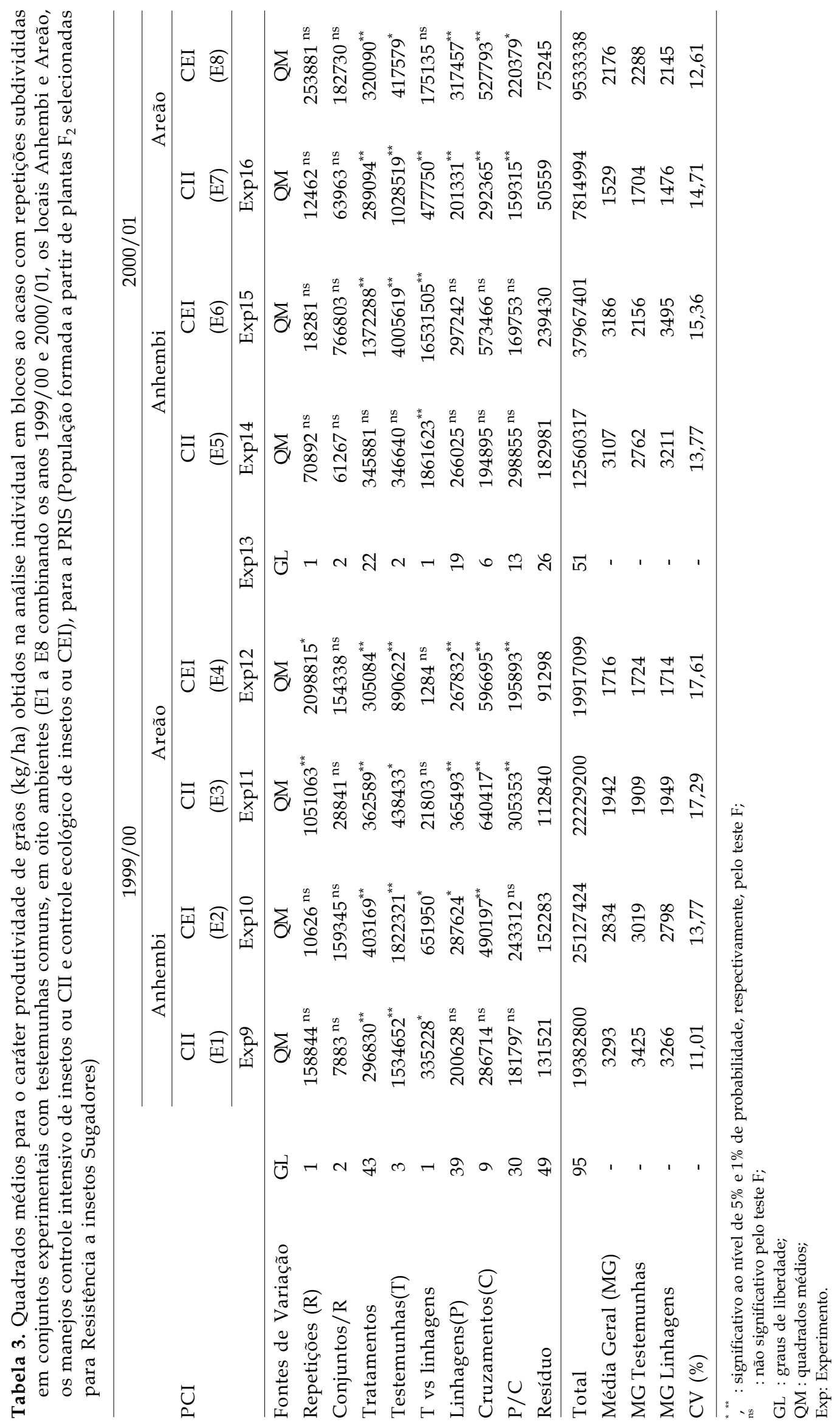




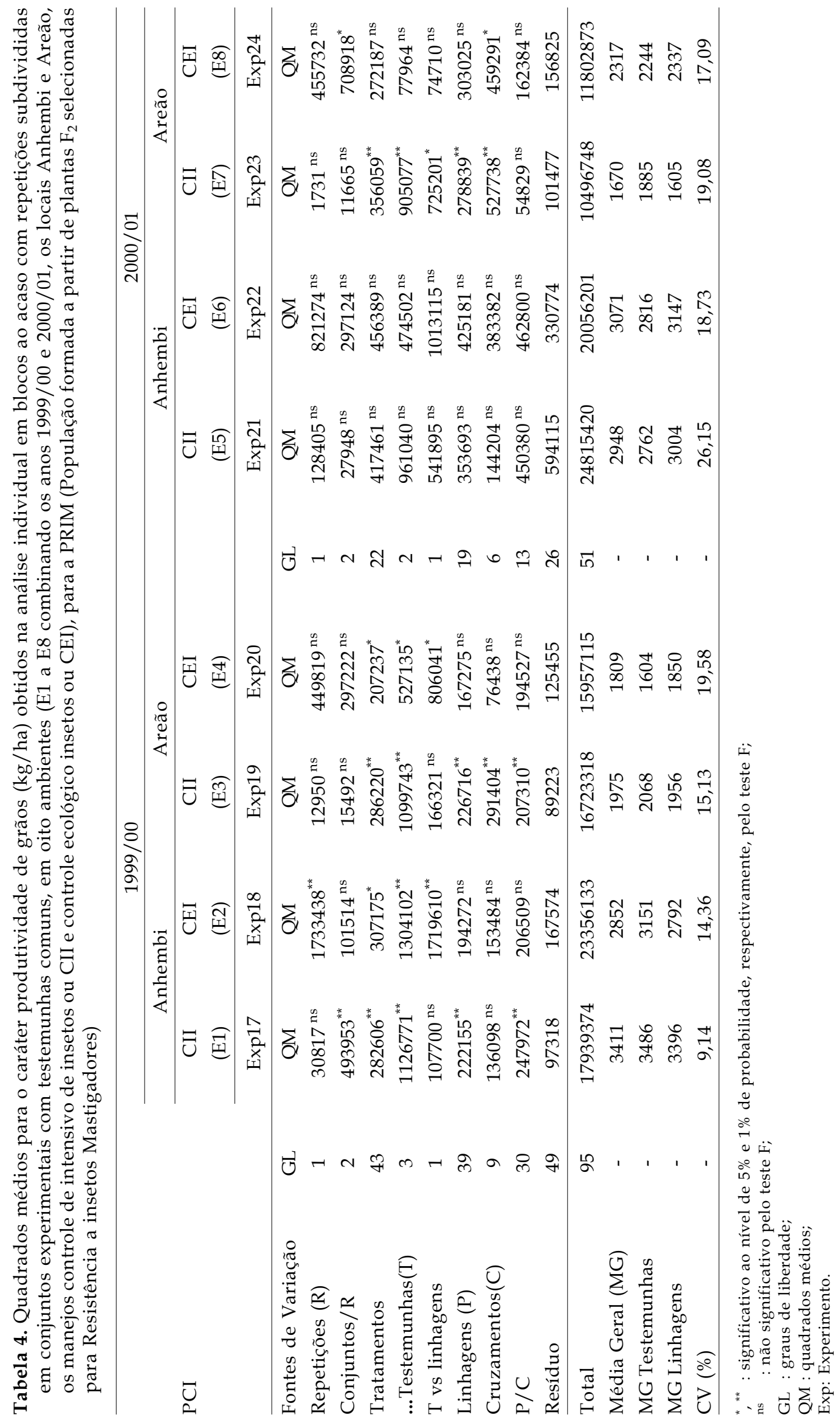


Tabela 5. Quadrados médios para o caráter produtividade de grãos $(\mathrm{kg} / \mathrm{ha})$ obtidos na análise conjunta de três populações de soja (PCI, PRIS e PRIM) sem desdobramento (genótipos incluem linhagens e testemunhas comuns) em blocos ao acaso com repetições subdivididas em conjuntos experimentais com testemunhas comuns

\begin{tabular}{|c|c|c|}
\hline Fontes de Variação & GL & QM \\
\hline Populações (Pop) & 2 & $299451^{\text {ns }}$ \\
\hline Genótipos(G)/Pop & 129 & $515867^{* *}$ \\
\hline Manejos(M) & 1 & $797605^{*}$ \\
\hline Pop $\times$ M & 2 & $1270539^{* *}$ \\
\hline$M \times G / P o p$ & 129 & $215855^{*}$ \\
\hline $\operatorname{Anos}(\mathrm{A})$ & 1 & $937^{\mathrm{ns}}$ \\
\hline Pop $\times$ A & 2 & $227554^{\mathrm{ns}}$ \\
\hline$A \times G /$ Pop & 66 & $552559^{* *}$ \\
\hline $\mathrm{M} \times \mathrm{A}$ & 1 & $46638843^{* *}$ \\
\hline Pop $\times \mathrm{M} \times \mathrm{A}$ & 2 & $171692^{\mathrm{ns}}$ \\
\hline $\mathrm{M} \times \mathrm{A} \times \mathrm{G} / \mathrm{POP}$ & 66 & $208446^{\mathrm{ns}}$ \\
\hline Locais (L) & 1 & $553816368^{* *}$ \\
\hline Pop x L & 2 & $497113^{\mathrm{ns}}$ \\
\hline L x G/Pop & 129 & $248435^{* *}$ \\
\hline $\mathrm{M} \times \mathrm{L}$ & 1 & $14244798^{* *}$ \\
\hline Pop $\times \mathrm{M} \times \mathrm{L}$ & 2 & $1189294^{* *}$ \\
\hline$M \times L \times G / P o p$ & 129 & $241139^{* *}$ \\
\hline$A \times L$ & 1 & $761327^{*}$ \\
\hline Pop $\times A \times L$ & 2 & $1622544^{* *}$ \\
\hline$A \times L \times G / P o p$ & 66 & $565353^{* *}$ \\
\hline $\mathrm{M} \times \mathrm{A} \times \mathrm{L}$ & 1 & $3037683^{* *}$ \\
\hline Pop $\times$ M $\times A \times L$ & 2 & $79435^{\mathrm{ns}}$ \\
\hline$M \times A \times L \times G / P o p$ & 66 & $278802^{* *}$ \\
\hline Repetições(R)/ M / A / L & 8 & $289257^{\mathrm{ns}}$ \\
\hline Conjuntos/ M / A / L / R & 16 & $220199^{\mathrm{ns}}$ \\
\hline Resíduo Médio & 942 & 167287 \\
\hline CV (\%) & - & 16,4 \\
\hline \multicolumn{3}{|c|}{$\begin{array}{l} \\
\text { pelo teste } \mathrm{F} ; \\
\text { ns } \\
\quad \text { : não significativo pelo teste } \mathrm{F} ; \\
\mathrm{GL}: \text { graus de liberdade; } \\
\mathrm{QM} \text { : quadrados médios }\end{array}$} \\
\hline
\end{tabular}

Observa-se empate relativo entre os dois grupos (testemunhas e linhagens), pois em 12 experimentos (seis com contrastes significativos) as testemunhas foram mais produtivas, enquanto nos outros 12 experimentos (também seis com contrastes significativos) as linhagens foram mais produtivas que as testemunhas.

\section{Análises Conjuntas}

Em comparação à análise individual de variâncias (Tabelas 2 a 4), a análise feita conjuntamente é mais arrojada em detectar efeitos
Tabela 6. Quadro simplificado de quadrados médios para o caráter produtividade de grãos ( $\mathrm{kg} / \mathrm{ha})$, obtidos na análise conjunta de três populações de soja (PCI, PRIS e PRIM) com desdobramento considerando apenas as linhagens $(\mathrm{P})$, em blocos ao acaso com repetições subdivididas em conjuntos experimentais com testemunhas comuns

\begin{tabular}{|c|c|c|}
\hline Fontes De Variação & GL & QM \\
\hline Populações (Pop) & 2 & $299451^{\text {ns }}$ \\
\hline Linhagens $(\mathrm{P}) /$ Pop & 117 & $421227^{* *}$ \\
\hline Manejos(M) & 1 & $797605^{*}$ \\
\hline Pop X M & 2 & $1270539^{* *}$ \\
\hline ...M X P/Pop & 117 & $199564^{\mathrm{ns}}$ \\
\hline $\operatorname{Anos}(\mathrm{A})$ & 1 & $937^{\mathrm{ns}}$ \\
\hline Pop X A & 2 & $227554^{\mathrm{ns}}$ \\
\hline ...A X P/Pop & 55 & $286608^{* *}$ \\
\hline $\mathrm{MXA}$ & 1 & $46638843^{* *}$ \\
\hline Pop X M X A & 2 & $171692^{\mathrm{ns}}$ \\
\hline M X A X P/Pop & 55 & $155736^{\mathrm{ns}}$ \\
\hline Locais (L) & 1 & $553816368^{* *}$ \\
\hline Pop X L & 2 & $497113^{\mathrm{ns}}$ \\
\hline L X P/Pop & 117 & $190765^{\mathrm{ns}}$ \\
\hline $\mathrm{M} \times \mathrm{L}$ & 1 & $14244798^{* *}$ \\
\hline Pop X M X L & 2 & $1189294^{* *}$ \\
\hline MX L X P/Pop & 117 & $223054^{*}$ \\
\hline $\mathrm{A} \times \mathrm{L}$ & 1 & $761327^{*}$ \\
\hline Pop X A X L & 2 & $1622544^{* *}$ \\
\hline A X L X P/Pop & 55 & $256856^{* *}$ \\
\hline $\mathrm{M} \times \mathrm{A} \times \mathrm{L}$ & 1 & $3037683^{* *}$ \\
\hline Pop X M X A X L & 2 & $79435^{\mathrm{ns}}$ \\
\hline MX A X L X P/Pop & 55 & $241798^{*}$ \\
\hline Repetições(R)/ M / A / L & 8 & $289257^{\mathrm{ns}}$ \\
\hline Conjuntos/ M / A / L / R & 16 & $220199^{\text {ns }}$ \\
\hline Resíduo Médio & 942 & 167287 \\
\hline CV (\%) & 16,4 & - \\
\hline \multicolumn{3}{|c|}{$\begin{array}{l}\text { : significativo ao nível de } 5 \% \text { e } 1 \% \text { de probabilidade, respectivamente, } \\
\text { pelo teste F; } \\
\quad \text { : não significativo pelo teste } \mathrm{F} ; \\
\text { GL : graus de liberdade; } \\
\text { QM : quadrados médios }\end{array}$} \\
\hline
\end{tabular}

significativos, em razão do maior número de graus de liberdade para o resíduo, além de permitir testar interações entre fontes de variação e contrastes de interesse do melhoramento genético.

$\mathrm{Na}$ análise conjunta de variâncias (Tabelas 5 e 6), a fonte de variação populações (POP) não proporcionou variabilidade genética significativa entre si. Este fato evidencia que a seleção praticada entre plantas $F_{2}$ para tolerância a insetos mastigadores (população PRIM) e insetos sugadores (população PRIS) não alterou a produtividade de grãos das plantas, relativamente à população-padrão, 
ou seja, com controle total de insetos em $\mathrm{F}_{2}$ (PCI). Três possíveis explicações podem ser consideradas. Em primeiro lugar, a seleção para tolerância a insetos entre plantas $F_{2}$ pode não ter sido eficiente; esta hipótese não deve ter ocorrido, pois foram verificadas diferenças significativas entre populações para reação a insetos sugadores, cujos dados não são apresentados nessa pesquisa. Em segundo lugar, ocorreu quebra entre os genes para tolerância a insetos e os genes que controlam a produtividade de grãos. Em terceiro lugar, a prática de seleção para produtividade de grãos e tolerância a fotoperíodo durante as diversas gerações de endogamia $\left(\mathrm{F}_{3}\right.$ a $\left.\mathrm{F}_{10}\right)$ pode ter anulado as diferenças entre populações para produtividade de grãos, possivelmente estabelecidas em $\mathrm{F}_{2}$.

A existência de variabilidade genética entre linhagens foi constatada tanto nas análises individuais (1999/ Areão/CII e 1999/ Areão/CEI para a população PCI, Tabela 3; 1999/Areão/CII, 1999/ Areão/CEI, 2000/Areão/CII e 2000/Areão/CEI para a população PRIS, tabela 2; 1999/Anhembi/CII e 1999/Areão/CII para a população PRIM, Tabela 3) quanto na análise conjunta (entre linhagens dentro de populações, Tabela 6). Este fato comprova que existe variabilidade remanescente dentro das populações, a qual poderá ser explorada em futuros ciclos de seleção. Além disso, esta variabilidade evidencia que as populações ainda não estão homogêneas, o que certamente dificulta a detecção de variabilidade significativa entre populações, conforme anteriormente relatado.

Além de linhagens dentro de populações, o exame associado das Tabelas 5 e 6 revela que a análise conjunta das três populações detectou como significativos os efeitos principais entre os dois sistemas de manejo (controle intensivo de insetos vs. controle ecológico de insetos) e entre os dois locais (Anhembi e Areão). Portanto, em termos de magnitudes relativa dos quadrados médios, os efeitos de locais e de manejos foram mais importantes que o efeito de anos agrícolas. Nas tabelas 5 e 6 também se verifica a existência de interações de primeira ordem, ou seja, entre os efeitos principais combinados dois a dois, com destaque para: populações $\times$ manejos, anos $\times$ linhagens dentro de populações, manejos $\times$ anos, manejos $\times$ locais e anos $\times$ locais. Observa-se que todas estas cinco interações significativas envolvem no mínimo um efeito principal significativo, fato este relativamente bem conhecido da literatura, isto é, se o efeito principal for significativo às interações duplas, triplas ou de maior ordem bem como os contrastes envolvendo seu efeito tende a apresentar significância também. Também foram detectadas interações significativas de ordem mais elevada, envolvendo três ou quatro efeitos principais: populações $\times$ manejos $\times$ locais, manejos $\times$ locais $\times$ linhagens dentro de populações, populações $\times$ anos $\times$ locais, anos $\times$ locais $x$ linhagens dentro de populações, manejos $x$ anos $x$ locais, manejos $x$ anos $\times$ locais $\times$ linhagens dentro de populações. É interessante notar a importância de manejos (M) (controle intensivo de insetos vs. controle ecológico de insetos) que foi significativo na análise conjunta (Tabelas 5 e 6), além de interagir de forma também significativa com a maioria dos feitos principais (POPxM, MxGenótipo(G)/POP, MxAnos(A), MxLocais(L), POPxMxLinhagens, MxLxG/POP, MxAxL, POPxMxAxL, MxAxLxG/POP (Tabela 4). Este fato abre a possibilidade de se utilizar o manejo diferenciado como um novo representante de ambientes nos experimentos dos programas de melhoramento de soja, além dos representantes tradicionais (locais, anos agrícolas, épocas de cultivo). A significância das interações de primeira, segunda e terceira ordens apontam para a importância de se considerar os efeitos principais envolvidos no detalhamento do estudo da interação $\mathrm{G} \times \mathrm{E}$, por exemplo, através das metodologias AMMI, BLUP/ REML e "bootstrap" por exemplo.

Verifica-se na tabela 7 que três dos 16 cruzamentos não contribuíram com linhagens $\mathrm{F}_{11}$ com alta produtividade de grãos, em nenhuma das três populações: 08-06 (IAS-5 x Lamar), 08-10 (Davis $x$ Lamar) e 08-14 (OCEPAR-4 x Lamar). Por outro lado, cinco cruzamentos destacaram-se com um número mais expressivo de linhagens $F_{11}$ selecionadas: 08-07 (IAS-5 x IAC-100) com 16 linhagens, sendo sete linhagens na PCI e nove linhagens na PRIS; 08-11 (Davis x IAC-100) com 11 linhagens, sendo oito na PRIS e três na PRIM; 0815 (OCEPAR-4 x IAC-100), com dez linhagens, todas na PRIM; 08-03 (BR-6 x IAC-100) com seis linhagens na PCI; 08-12 (Davis x D72-9601-1) com quatro linhagens na PRI. Certamente, esses cinco cruzamentos têm tendência para capacidade específica de combinação mais alta.

Pela tabela 7 , pode-se observar que alguns genitores destacaram-se com participações mais expressivas nos cruzamentos que originaram as sete linhagens $\mathrm{F}_{11}$ superiores de cada população. Em primeiro lugar, como maior destaque, classificou-se o genitor IAC-100 com 11 participações, sendo cinco em PRIS, três em PRIM e três em PCI. Em segundo lugar, classificaram-se os genitores D72-9601-1, BR-6 e Davis, com seis participações cada um; o genitor D72-96011 teve quatro participações em PRIM, uma em PRIS e uma em PCI; o genitor BR-6, teve todas as seis participações em PCI, e o genitor Davis mostrou três participações em PRIM e três em PRIS. 
Tabela 7. Identificação das linhagens e cruzamentos de maior destaque em cada população

\begin{tabular}{|c|c|c|c|}
\hline Populações & Símbolo das Linhagens & Número dos cruzamentos & Genitores \\
\hline \multirow{7}{*}{ PCI } & P20 & $08-07$ & IAS-5 x IAC-100 \\
\hline & P1 & $08-01$ & BR-6 x Crockett \\
\hline & P10 & $08-03$ & BR-6 x IAC-100 \\
\hline & P5 & $08-03$ & BR-6 x IAC-100 \\
\hline & $\mathrm{P} 2$ & $08-01$ & BR-6 x Crockett \\
\hline & P12 & $08-04$ & BR-6 x D72-9601-1 \\
\hline & $\mathrm{P} 4$ & $08-02$ & BR-6 x Lamar \\
\hline \multirow{7}{*}{ PRIS } & P7 & $08-07$ & IAS-5 x IAC-100 \\
\hline & P9 & $08-07$ & IAS-5 x IAC-100 \\
\hline & $\mathrm{P} 2$ & $08-07$ & IAS-5 x IAC-100 \\
\hline & P13 & $08-11$ & Davis $x$ IAC- 100 \\
\hline & P11 & 08-09 & Davis $x$ Crockett \\
\hline & P10 & $08-08$ & IAS-5 x D72-9601-1 \\
\hline & P18 & $08-11$ & Davis $x$ IAC -100 \\
\hline \multirow{7}{*}{ PRIM } & $\mathrm{P} 4$ & $08-12$ & Davis $x$ D72-9601-1 \\
\hline & P16 & $08-15$ & OCEPAR-4 x IAC-100 \\
\hline & $\mathrm{P} 20$ & $08-16$ & OCEPAR-4 x D72-9601-1 \\
\hline & P17 & $08-15$ & OCEPAR-4 x IAC-100 \\
\hline & P7 & $08-12$ & Davis $x$ D72-9601-1 \\
\hline & P5 & $08-12$ & Davis $x$ D72-9601-1 \\
\hline & P15 & $08-15$ & OCEPAR-4 x IAC-100 \\
\hline
\end{tabular}

Em terceiro lugar, classificou-se o genitor IAS5, com cinco participações, sendo quatro em PRIS e uma em PCI. Em quarto lugar, colocou-se o genitor OCEPAR-4, com quatro participações, todas em PRIM. Em quinto lugar, tem-se o genitor Crockett, com três participações, sendo duas em PCI e uma em PRIS. Finalmente, em sexto lugar, classificou-se o genitor Lamar, com uma única participação, sendo esta na PCI. Esta classificação relativa dos genitores reflete a capacidade geral de combinação deles mesmos. É muito encorajador o fato de todos os quatro genitores com resistência/tolerância a insetos terem sido incluídos entre os maiores destaques, em ordem decrescente de participações: IAC-100, D72-9601-1, Crockett e Lamar.

\section{CONCLUSÕES}

1. Nas três populações, existe variabilidade genética remanescente entre as linhagens.

2. O manejo diferenciado (CII vs. CEI) é um representante eficiente de ambientes diversos.

3. O local Anhembi destacou-se como de alta produtividade em todas as situações.
4. Para a capacidade de gerar linhagens superiores, sobressaíram-se os genitores IAC-100, D72-9601-1, BR-6, Davis e IAS-5.

5. Destaques especiais em produtividade envolveram os cruzamentos do genitor IAC-100 com IAS-5, Davis, OCEPAR-4 e BR-6. As linhagens de maior destaque em cada população foram: PCI (P20, P1, P10, P5, P2, P12 e P14), PRIS (P7, P9, P2, P13, P11, P10 e P18) e PRIM (P4, P16, P20, P17, P7, P5 e P 15). Estas linhagens são promissoras pela reunião das características de tolerância a insetos e produtividade simultaneamente.

\section{REFERÊNCIAS}

ARIEL, C.R.E. Aspectos biológicos e não preferência para alimentação e oviposição de Anticarsia gemmatalis Huber, 1818, em genótipos de soja, Glycine max (L.) Merrill. 1990. 160p. Dissertação (Mestrado) - Escola Superior de Agricultura "Luiz de Queiroz", Universidade de São Paulo, Piracicaba.

BELAND, G.L.; HATCHETT, J.H. Expression of antibiosis bollworm in two soybean genotypes. Journal of Economic Entomology, v.69, n. 4, p.557-560, 1976. 
BURDEN, D. J.; NORRIS, D. M. Ovarian failure induced in Epilachna varivestis by a 'death-trap' 'Davis' variety of Glycine max. Entomologia Experimentalis et Applicata, v. 73, n. 2, p. 183-186, 1994. Resumo em CAB Abstracts on CD-ROM, 1993-94.

IBGE: Instituto Brasileiro de Geografia e Estatística. Disponível em: http://www.ibge.gov.br/home/estatistica/indicadores/ agropecuaria/lspa/defaulttab.shtm. Acesso em 11 de junho de 2008.

SOUZA, R.F.; TOLEDO, L.F.F. Genetic analysis of soybean resistance to stink bug. Revista Brasileira de Genética, Ribeirão Preto, v.18, n.4, p.593-598, 1995.

STATISTICAL ANALYSIS SYSTEM. SAS, version 8.0. Cary, North Carolina: The SAS Institute, 1999.

VELLO, N.A. Ampliação da base genética do germoplasma e melhoramento de soja na ESALQ/USP. In: SIMPÓSIO SOBRE A CULTURA E PRODUTIVIDADE DA SOJA, Piracicaba, 1991. Anais... Piracicaba: FEALQ, 1992. p. 60-81 